Article

\title{
Changing the Educational Culture of the Home to Increase Student Success at School
}

\author{
Kenneth Leithwood * and Penny Patrician \\ Leadership, Higher and Adult Education in Education, Ontario Institute for Studies in Education, \\ University of Toronto, 252 Bloor Street West, Toronto, ON M5S 1V6, Canada; \\ E-Mail: penny.patrician@mail.utoronto.ca
}

* Author to whom correspondence should be addressed; E-Mail: kenneth.leithwood@utoronto.ca; Tel.: +1-905-294-5251.

Academic Editor: Gregor Wolbring

Received: 2 July 2015 / Accepted: 16 September 2015 / Published: 18 September 2015

\begin{abstract}
Parent involvement in their children's learning is widely acknowledged as having a positive effect on student academic success. Of particular relevance is the finding that the influence of parent engagement can mitigate differences in socioeconomic status (SES) and family background. Family background is a multi-dimensional concept that includes the family's "educational culture" (including for example, parenting style, parental expectations for children's work at school, direct instructional support for school learning, active parent interest in the school's curriculum, and the monitoring of children's engagement with their school work). It is these features of a child's home environment that directly influence much of the social and intellectual capital students need to be successful at school. This paper summarizes a quasi-experimental field study which explored the relative effects of alternative types of school interventions on parent engagement. All of these interventions aimed to further engage parents in the education of their children as a means of both improving student achievement and closing gaps in achievement for students living primarily in challenging social and economic circumstances. Initiatives by school staffs aimed at helping those families struggling to build productive educational cultures in their homes would appear to be a very promising strategy for closing achievement gaps between advantaged and disadvantaged students. The study provides eight lessons other districts might take heed of as they embark on their own parent engagement interventions.
\end{abstract}


Keywords: parental engagement; home interventions; educational culture; student learning

\section{Introduction}

\subsection{Background}

Considerable evidence suggests that family background accounts for a substantial proportion of variation in student achievement [1]. Family background is a multi-dimensional concept that includes some features which are largely unalterable in the short- to mid-term (usually referred to as SES) such as family income and parental education. Other features associated with family background are alterable, however; together, these alterable features are often referred to as the family's "educational culture" [2].

The educational culture of the home includes, for example, parenting style, parental expectations for children's work at school, direct instructional support for school learning (e.g., parents reading with their children at home), active parent interest in the school's curriculum, and the monitoring of children's engagement with their school work [3]. It is these features of a child's home environment that directly influence much of the social and intellectual capital students need to be successful at school [4-6].

A family's educational culture is often strongly associated with parental income, education and other relatively hard-to-change family features. While some families with low incomes and only modest parental education manage to develop very strong educational cultures in their homes, this is difficult to do and is clearly the exception without some kind of help from others. School staffs, research now demonstrates, are capable of being the "others" who assist those parents to build strong educational cultures in their homes [7]. Indeed, initiatives by school staffs aimed at helping those families struggling to build productive educational cultures in their homes would appear to be a very promising strategy for closing achievement gaps between advantaged and disadvantaged students.

Parent involvement in their children's learning is widely acknowledged as having a positive effect on student academic success (e.g., [5,8-11]). Of particular relevance is the finding that while all students benefit from family involvement in education, the influence of parent engagement can mitigate differences in socioeconomic status (SES) and family background $[5,12,13]$.

The work described in this paper, a quasi-experimental field study, originated in a series of discussions with directors of education (CEOs) in Ontario about manageable ways of closing achievement gaps in their districts. Readings of a sample of the literature on parent engagement (e.g., $[7,14]$ ) led directors to the view that a manageable approach to such gap closing might include developing an ongoing relationship, in schools serving significant numbers of "high needs" students, with a small sample of the most challenged parents and students along with their teachers, actively supported by one or more members of the school staff. The aim of these relationships would be to help parents further develop selected features of their "family educational cultures" conducive to student success at school; this relationship was to be enacted wherever it seemed most comfortable for the parents, possibly in the school but possibly in home or community environments also. 
Directors in seven districts each selected a small team to lead their district's participation in the project. Working with the project director and staff in several schools, these district teams helped schools develop strategies for enhancing a small number of the most promising features of home educational cultures; implement these strategies with a small number of families in their schools; monitor the implementation of those strategies, making appropriate mid-course refinements; and assess the effects of these strategies on family educational cultures. The design and conduct of the project included important features of both a quasi-experimental field study (described more fully below) and action research, as well.

Reflecting a central feature of action research was adherence, in the design and conduct of the project, to strong preferences and beliefs of those enacting the project. In this case such preferences and beliefs took the form of three broad principles:

- All students are capable of learning to relatively high levels given suitable opportunities and supports. Many times during the initial project meeting, mention was made of small but significant numbers of staff who, although often espousing this belief, do not act in accordance with it. In their study of school-family relations, Cooper et al. [15] observe that, out of lack of familiarity with the values, beliefs and practices of diverse families, some educators may make stereotypical assumptions about families and communities resulting in low expectations and other deficit-based practices (p. 761). Because authentically held high expectations for student success are so important to the improvement of student learning, this belief was considered to be a fundamental starting point for all staff members involved in the project (and a goal to work toward with all parents and students participating in the project).

- All parents want the best for their children. District team members noted a complete absence, in their experiences, of parents not wanting the best for their children. That said, there is considerable variation in what "the best" actually means among parents. Such variation can be accounted for by differences, for example, in parents' own school experiences, the importance of education in parents' own employment and broader life opportunities, cultural and religious values, knowledge of possible futures for their children, and the like. So all parents have altruistic aspirations for their children, although those aspirations often look quite different. This belief directed project staff to focus their efforts on differences in what parents viewed as "the best" - not on whether or not parents want the best for their children.

- All parents, and the home environments they create, include assets of significant value to the success of their children at school. There are enormous differences in especially the surface features of children's home environments. These surface features are often a product of families' economic circumstances. Because this project was aimed at helping parents, many of whom were economically challenged, the surface features of some of their home environments were expected to include, for example, crowded physical spaces, uncertain housing arrangements, limited availability of education-related resources such as books, scarce opportunities for parent-child interaction because of work demands, and limited access to food that is high in nutritional value.

These home features clearly do present indirect challenges to students' school success. But as Jeynes concluded from his meta-analysis of relevant research, "some of the most potent facets of 
parent involvement are among the more subtle aspects of family support" [13] (p. 262). Most notably, parental expectations and style each demonstrate strong relationships with scholastic outcomes. It was not, according to Jeynes' synthesis of research, particular actions by parents but "a general atmosphere of involvement [that] produced the greatest results" for students at school (p. 262). This belief discouraged project staff from adopting a deficit view of family environments unlike those they were used to and typically valued.

Schools often do not know either what those family assets are and/or how to build on them for the improvement of student learning. In addition to a "generally involved atmosphere" available to some children, no matter their economic circumstances, families involved in this project were likely to have unique cultures, traditions and social networks that schools could build on in their efforts to help children make sense of the school curriculum. One of the challenges for the project was to identify those assets and determine how best to use them in the interests of helping children succeed at school. This belief encouraged project staff to seek out aspects of each family's environment that could be used to help build student success at school.

\subsection{Objectives}

Three sets of parent engagement goals were established for project schools: these goals directed project schools to the elements of "family educational culture" that contribute most to student success at school.

\subsubsection{Fostering High Expectations among Parents for Their Children's Success at School}

Parental expectations were defined for purposes of this project as "The degree to which a student's parents [hold] high expectations of the student's promise of achieving at high levels" [13] (p. 246). Personally held and challenging but achievable goals (or expectations) are at the heart of most contemporary theories of human motivation (e.g., [16]), theories with application in many fields. Such theory and related evidence is reflected, for example, in the Ontario Leadership Framework which points to the establishment of high expectations among staff and students as an essential leadership practice. Many people, whether children or adults, either rise or fall to the level of expectations that valued others have for them; their own goals and sense of confidence about what is possible for them are, to a great extent, socially constructed. Consistent with this theory, Jeynes' [13] meta-analysis identified "parental expectations", among all forms of parental involvement in school, as having the greatest impact on student achievement by a large margin; a significant effect size of 0.58 [13] (p. 253). At least a significant proportion of parents to be involved in this project had struggled at school themselves, may not perceive much real-life value from their own schooling experience, and may have difficulty envisioning a future for their children that would depend on relatively high levels of school success (see [17] for a discussion of barriers to parental involvement in their children's education). So an important set of tasks to be accomplished by those implementing the project in their schools was to identify the existing expectations parents have for their children's schooling, persuade parents that their children are capable of high levels of achievement, and extend parents' views of what is possible for their children when they are successful at school. 


\subsubsection{Creating Effective Communication between Parents and Their Children in the Home}

Schools typically spend considerable effort on creating meaningful ways of communicating with parents [4]. Efforts such as these include school newsletters, curriculum nights at school, online messaging systems and the like. While these communication efforts remain important, it is the communication between parents and their children that is of most concern to this project. Underlying most such communication is what the literature refers to as "parenting styles." While it may seem presumptuous to view parenting styles as something schools might influence, the styles described in this literature are centrally defined by different approaches to communication between parents and their children. In his meta-analysis, Jeynes, [13] defines parenting style as "The extent to which a parent demonstrates a supportive and helpful parenting approach" [13] (p. 246). So creating effective parent/child communications necessarily entails clarifying with parents the advantages of adopting a supportive yet firm approach to interacting with their children, as compared with more extreme forms of either autocratic or laissez-faire approaches.

Overt, direct discussions of parenting styles between parents and school staffs may go beyond the boundaries of what parents will accept from schools and what some schools staffs will feel is a legitimate part of their role. So creating effective parent/child communications about school-related matters required project staff to focus on how productive parenting styles are applied to obviously school-relevant issues.

\subsubsection{Building Family's Social and Intellectual Capital Related to Schooling}

The basic concepts framing this project objective are reviewed by Bolivar and Chrispeels [7]; and explored by Lee and Bowden [18], for example. Social Capital was defined as the power and information present in parents' social relationships that can be used to leverage additional resources helpful in furthering their children's success at school. Often considered key to the building of social capital are three mechanisms [19]: trust; access to sources of information that promote the common good over individual self-interest and; norms and sanctions within a community that promote the common good over individual self-interest. According to Ferlazzo [20], "The more people do for themselves, the larger community social capital will become, and the greater will be the dividends upon the social investment" (p. 11).

Intellectual capital was defined as the knowledge and capabilities of parents with the potential for collaborative action. Evidence from Hoover-Dempsey and Sandler's [21] review of psychological theory and research about why parents become involved in their children's education, shows that parent engagement is nurtured when parents believe they should be involved in their children's education and schooling and have a positive sense of efficacy about the usefulness of their involvement (p. 27). Many low income parents who were likely to be part of this project differed from middle income parents in two ways that help explain differences in their children's potential for success at school [7]. Low income parents often are unable to gain access to and benefit from the resources available in the school; they are less familiar with the "grammar of schooling" [3], for example. In addition, they often do not have opportunities for taking forms of collective action which 
foster the exchange and development of collective knowledge or intellectual capital; working two or three jobs to "make ends meet" reduces the time available to interact with other parents, for example.

In pursuit of this project objective, school staffs provided structures for face-to-face meetings with parents to improve parents' understanding of the school's expectations for their children, as well as manageable ways in which parents can help at home. While the content of these experiences differed in response to unique parent group needs, common across all schools were opportunities for parents to learn more about general curriculum expectations for the grade in which the child is enrolled; the school's assumptions about school work that the student will do at home; teachers' general approaches to instruction; how student behavior is managed in the classroom and across the school; and types of student testing to be implemented over the year.

This project objective was also pursued by creating and maintaining parent peer networks (explored by $[22,23]$ ). Most project schools provided parents with encouragement and opportunities to interact with other project parents about the challenges they faced in providing a productive family educational culture for their children, how those challenges might best be met, and what school personnel might do to help.

\subsection{Framework}

The project as a whole tested claims about the effects of the three different, but by no means mutually exclusive, approaches to improving the engagement and achievement of students in challenging circumstances as described above. These claims can be represented, in summary form, as a "theory of action", as in Figure 1, which also points to the types of data that would needed if all of the project's claims were to be tested. As this figure suggests, parent engagement initiatives implemented by project schools were intended to have a positive influence on two sets of conditions important for student success - family educational cultures (FEC: high expectations, social/intellectual capital, communication) and the school and classroom conditions (SCC) of those students selected to be in the project (as well as the relationships between family and school) ${ }^{1}$.

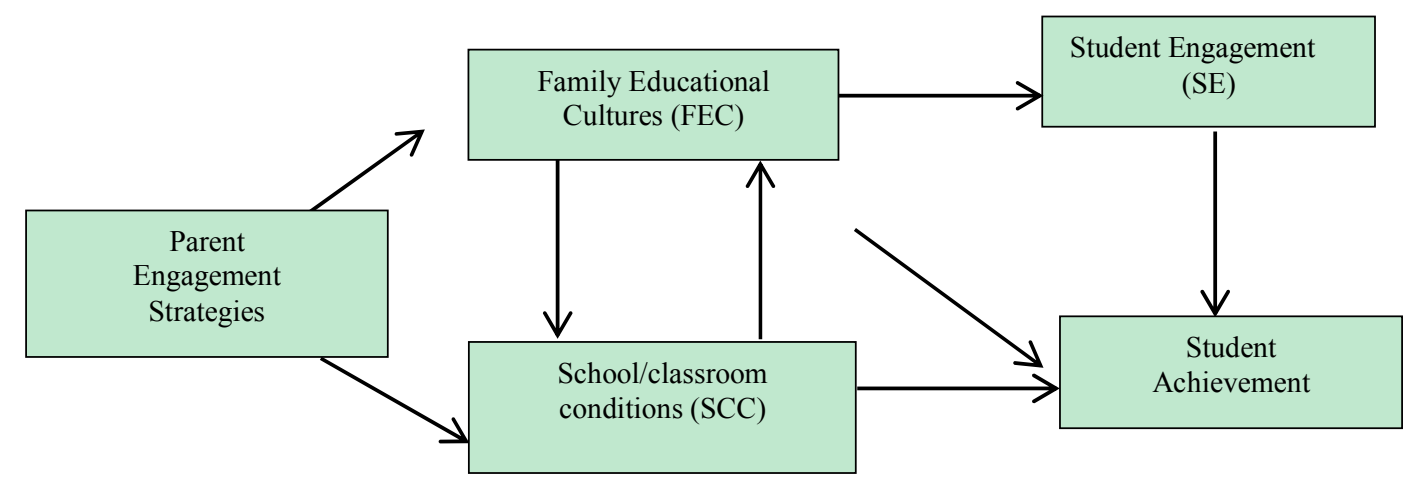

Figure 1. The Project's Theory of Action.

1 Based on Bronfenbremmer's [24] bioecological model, Niehaus \& Adelson [25] view these two sources of influence on children's achievement as microsystems and mesosystems which, together, account for most of the "potential risk and protective factors ....highly important to students' performance and well-being" (p. 812). 
A positive influence on both these variables is expected, in turn, to enhance students' engagement (SE) with school, as well as their achievement. Some of the influence of family and both school and classroom conditions will have direct effects on achievement while some will have indirect effects that are mediated by student engagement ${ }^{2}$. Similarly, improvements in family educational cultures are expected to result in more fully engaged students through their additional motivation to succeed, as well as improved student achievement as a result of increased parental expectations, communication, and the social and intellectual capital provided by families.

While school and classroom conditions were an important part of the framework for the study, as Figure 1 suggests, labour conditions in the province at the time of project implementation prevented all but one district from collecting data about this variable and these data are not reported.

\section{Methods}

A pre-test, post-test control group design was used in each of the seven district projects, although there was considerable variation especially in the selection of parents and students to act as control groups ${ }^{3}$. The project on which this study is based was initiated jointly by directors of education of the participating districts. Each of the individual participating districts followed the ethical review procedures established in their own districts. Project funding was provided by the Ministry of Education and the first author led the project team.

\subsection{Sample}

This section outlines a set of modal decisions around which each district's sampling plan varied. Districts were asked to approximate, as best they could, the modal decisions described in this section and, with a few quite important exceptions, this was largely accomplished by the participating districts.

Grade levels. Each district was asked to include at least 3 children and one or both parents in each of 3 classrooms in each of about four schools (36 student/parent dyads). While, in principle, there was no restriction placed on the grades to be involved, two guidelines were provided to help ensure the availability of suitable data.

First, district teams were asked to make sure that whatever grades were selected, there would be access to reliable information about achievement at both the beginning and at or near the end of the 12-month project period. This guideline turned out to be difficult to follow partly because the province's labor challenges unexpectedly delayed the start of most projects and partly because of the minimal use that could be made of provincial test results given the grade levels of participating students and the schedule for reporting Ontario's Education Quality and Accountability Office (EQAO) student assessment results.

Second, district teams were asked to avoid selecting grades for which only report card data about achievement was available. While such data may be very reliable in some schools, it is widely believed

\footnotetext{
2 In this study of parent engagement, student engagement is one of three outcomes used to assess the effects of changes in three components of family educational culture. For a discussion of the influence of school and classroom practices on student engagement, see for example the research series of Dunleavy, Willms, Milton and Friesen [26].

3 The full report of results (Leithwood et al, [27]) includes individual district reports. These individual reports provide more detail about samples and sample selection.
} 
to be unreliable in many schools and so provides unconvincing evidence of project effects on achievement. That said, report card data should be included with the other data about achievement that is collected ${ }^{4}$. As it turned out, report card data (about subject achievement and learning skills) were the only achievement data available to most districts and not all districts provided such data as part of their reports.

Student and parent background. As much as possible, districts were asked to consider four criteria when selecting student/parent dyads for project participation:

- Students are struggling academically: this could mean that they have been achieving at levels 1 or 2 on at least several EQAO measures over multiple testing cycles without showing signs of improvement, for example;

- Students are less engaged in school than is needed for success: this could mean significantly below average attendance rates and/or unusually disruptive behavior in school, for example;

- Parents are facing significant social and/or economic challenges: social challenges could include, for example, limited formal education, being a single parent, and being a new immigrant without a support network in the community; economic challenges could include, for example, income at or below the poverty line, an occupation providing little time for engagement with their children and unstable housing accommodation;

- Parents have either low or no explicit expectations for their children's success at school. These expectations may be known by school staff as a result of their previous contact with parents.

Districts were asked to ensure the selection of student/parent dyads that met as many of these four criteria as possible based on credible sources of evidence and profiles of each student/parent dyad were developed before the project began to be implemented in each district. All districts were able to follow these four guidelines.

Control student/parent dyads. Participating districts were asked to address three important challenges when selecting control student/parent dyads and they were largely successful in doing this:

- ensuring comparability of the dyads on the selection criteria outlined above;

- minimizing the risk of "treatment contamination" or influence from project schools' parent engagement initiatives;

- gaining reasonable access to, and cooperation of, the control student/parent dyads.

\subsection{Measures}

Student survey. This survey instrument provided the most direct evidence about achievement of the three project goals and was used by all district teams. Appendix A describes items included in the survey which was used to measure two dimensions of student engagement (behavioral and psychological) and the three components of family educational culture selected as key outcomes for the project. Many of these items were originally based on Jeremy Finn's [29] model of school engagement adapted for research on school leader effects on student engagement (see for example [30]). Finn's model defines engagement as having both behavioral and psychological dimensions.

4 As a result of his series of meta-analyses, Jeynes [28] has observed that parent engagement initiatives typically have significantly larger effects on report card scores than on standardized achievement test results. 
The behavioral dimension comprises four "levels" of behavior-responding to requirements, engaging in class-related initiatives, participating in extra-curricular activities, and being involved in school decision making (through student councils and the like): previous evidence suggests that the fourth of these types of engagement has no effect on achievement and so items measuring such engagement were not used by most districts. Students' psychological engagement or identification with school includes both a sense of belonging at school as well as valuing school ${ }^{567}$. Some features of this survey were slightly modified (reduced numbers of items measuring some variables, simplified language) by several districts to accommodate unique local conditions.

Report card student achievement measures. Achievement measures depended, in part, on the grade of the students selected for the project. Each district team was asked to specify which existing sets of achievement data would be used as their pre- and post-measure of achievement. However, initial guidelines about measures of achievement, notwithstanding, several districts did not report achievement data at all while the remainder relied exclusively on report card evidence about subject achievement (all schools in Ontario use a common report card developed by the province).

Report card student learning skills measures. The province's common report card also requires teachers to provide an assessment of each student's "learning skills" including collaboration, independent work, initiative, organization, responsibility and self-regulation.

Parent interviews. Each school engaged in discussions with parents about their interest in participating in the project. Parents selected to be part of the study were interviewed at two points during the project (e.g., after 3 months and after 6 months). These interviews asked the following questions:

- To this point, what does participating in your school's parent engagement project involve for you?

- Please describe how you have been involved in each aspect of the project?

- To what extent has each aspect of your project involvement been useful to you?

- In particular, what has this involvement meant for your relationships with your child's school?

- What has this involvement meant for you and your child's interactions about school in your home?

- What aspects of the project have been most and least helpful for you?

- Do you have any suggestions for changes to the project that it would make it more useful for you?

Student interviews. Interviews with students selected to be part of the study also took place at two points during the project, as with parents. Questions for these interviews included at least the following:

- Since you became part of your school's parent engagement project (some other designation may be needed for students) is anything different for you at school? If so, what?

5 While scale reliabilities for this instrument could not be calculated from the data in this project, previous data sets have indicated reliabilities (Cronbach's Alpha) for all scales significantly above minimum acceptable levels (0.60).

6 Also see Turner et al. [31] for a comparable theoretical account of factors contributing to student engagement.

7 For a discussion of the relationships between student engagement and family and school factors see Willms [32]. 
- Do you and your parents approach your school work any differently now than before? If yes, what is the difference?

- Do you and your teacher(s) approach your school work any differently now than before? If yes, what is the difference?

- What else could be done by the school or by your parents to help you do better at school?

School staff interviews. Interviews with school staffs who are part of each school's project implementation team were conducted during the same time period suggested for parents and students. Questions suggested for these interviews included:

- What challenges have you encountered while implementing your school's parent engagement project?

- How have you addressed the most significant of these challenges?

- Can you detect much difference in parental support for the students in your class/school who are participating in the project?

- Have you changed your approach to these students in your classroom practices? If so, how?

- What could the project do differently that would make it more effective in your view?

\section{Results}

\subsection{Selected Objectives}

Table 1 summarizes the objectives each district established for its project. Developing the social capital of parents related to schooling was selected by five of the seven districts and improving communication in the home between parents and students was selected by three. Only D3 explicitly set out to increase parents' expectations for student success at school. All districts had additional objectives mostly concerned with building awareness among staff about the importance of parent engagement and developing the capacities of staff needed to enhance parent engagement in their classrooms, schools and the homes of their students.

Table 1. Objectives Selected by Districts for their Parent Engagement Interventions.

\begin{tabular}{cc|c|cc}
\hline & \multicolumn{3}{c}{ Objectives } \\
\cline { 2 - 5 } Districts & $\begin{array}{c}\text { Increasing Parental Expectations } \\
\text { for Students' Success at School }\end{array}$ & $\begin{array}{c}\text { Developing the Social Capital of } \\
\text { Parents Related to Schooling }\end{array}$ & $\begin{array}{c}\text { Improving Communication between } \\
\text { Parents and Students in the Home }\end{array}$ & Other \\
\hline D1 & & $\sqrt{ }$ & $\sqrt{ }$ \\
D2 & $\sqrt{ }$ & $\sqrt{ }$ & $\sqrt{ }$ & $\sqrt{ }$ \\
D3 & & $\sqrt{ }$ & $\sqrt{ }$ \\
D4 & $\sqrt{ }$ & $\sqrt{ }$ & $\sqrt{ }$ \\
D5 & & & $\sqrt{ }$ \\
D6 & & $\sqrt{ }$ & $\sqrt{ }$ \\
D7 & & & & $\sqrt{ }$ \\
\hline
\end{tabular}




\subsection{Selected Interventions}

Districts and many of their schools exercised considerable autonomy in making decisions about the specific parent engagement strategies they would use for their version of the project. However, project teams were provided with background literature about parent engagement strategies and several districts had significant experience with many such strategies already. A summary of the strategies used by each district is provided in Table 2 below. Because of the fundamental nature of the project, all such strategies were, by definition, "school driven" rather than "parent driven", a distinction discussed by Ma and colleagues [6]; they were also targeted at one or more of the three overall project outcomes as indicated in Table 1 above.

In a wide-ranging review of relevant research, Leithwood and Jantzi [33], identified three broad categories (including thirteen specific forms) of parent engagement strategies. One of these categories encompassed seven specific forms of school-initiated parent engagement strategies, four of which were used by some project schools including:

- Assisting parents in child rearing skills (e.g., D7);

- Assisting parents in instructional skills (e.g., D2);

- Communicating with parents about school-related matters such as school programs, activities, things studied in class (D1, D6);

- Advising parents on assisting child with homework (D4).

Table 2. Summary of Interventions Used by Districts.

\begin{tabular}{|c|c|}
\hline Districts & Nature of Project Interventions \\
\hline D1 & $\begin{array}{l}\text { - Parent "how-to" guides including questions to ask at parent-teacher interviews } \\
\text { - Teacher in-service } \\
\text { - Series of meetings in school with parents to address parent-identified needs } \\
\text { - Individual parent consultations by teacher to facilitate parent contact with school } \\
\text { - Multiple avenues used to keep parents informed of important school dates and other activities in which their } \\
\text { children were involved }\end{array}$ \\
\hline D2 & $\begin{array}{l}\text { In three project schools } \\
\text { - Parents and students meet in school four or five times to explore learning strategies especially in math and literacy } \\
\text { Summer program: } \\
\text { - Developing literacy and numeracy skills for students } \\
\text { - Helping parents with ways of assisting such learning in the home } \\
\text { - Instruction in native languages }\end{array}$ \\
\hline D3 & - Develop and support parent-directed groups that met once or twice per week \\
\hline D4 & $\begin{array}{l}\text { - Creation and use of a communication book } \\
\text { - Face-to-face conversations with parents by staff } \\
\text { - Telephone conversations with parents by staff } \\
\text { - Formally scheduled classroom visits }\end{array}$ \\
\hline D5 & $\begin{array}{l}\text { - Responding to parent focus group } \\
\text { - In-service for educators } \\
\text { - Community evening family engagement group } \\
\text { - Literacy sessions }\end{array}$ \\
\hline
\end{tabular}


Table 2. Cont.

\begin{tabular}{ll}
\hline Districts & Nature of Project Interventions \\
\hline & - Math, literacy, arts nights with parents \\
& - BBQ \\
D6 & - Movie nights, games nights, community walk \\
& - Personal phone calls/invitations to parents \\
& - Use of social media to inform parents of student work \\
\hline & - Hire "student asset" coaches who meet for one hour and 30 min twice a week with parents in the home \\
D7 & - Meeting in school for all parents served by asset coaches (dinner, engage with children in "play" activity, \\
& free passes for selected community activities) \\
\hline
\end{tabular}

Not used by any project schools were three strategies in this category that most evidence suggests, have little bearing on student outcomes in schools [8]:

- Involving parents as school volunteers;

- Involving parents in school-community collaborations;

- Involving parents in school decision-making through PTA, school councils and the like.

A second category of parent engagement strategies, shared forms of school-parent engagement, includes just one strategy, communication between parents and school. This strategy was part of all districts' intervention strategies; it was especially central to initiatives undertaken in D6.

Parent-initiated types of engagement, a third category, includes five specific strategies. Although project schools, not parents, initiated all of the strategies studied, some of those initiatives aimed to prompt some forms of parent initiation including:

- Communicating with one's child about schooling including the frequency of parental talk with one's child about school, high school plans, post high school plans, help with homework and the like (e.g., D7);

- Communicating with one's child about educational aspirations such as how far in school parents want their child to go (e.g., D7);

- Providing academic stimulation at home, not necessarily related to the school curriculum (e.g., D6);

- Supervising child's activities to ensure education as priority by setting guidelines about how often parent checks homework, limiting the frequency child is allowed to go out with friends, amounts of TV/Internet/video game/music time as well as how late they can be used (e.g., D4);

- Contacting the school about, for example, academic programs, child's behaviour and child's school performance (e.g., D6).

In sum, schools in the project districts, as a whole, implemented about two-thirds of the thirteen specific interventions described in previous research. Prior evidence [8] indicates that most of the strategies not used have little or no demonstrable effect on student outcomes. So their choice of intervention strategies provided districts with a promising start on accomplishing their chosen goals. 


\subsection{Parent, Student and Teacher Interview Results}

All districts collected interview evidence from parents, teachers and students involved in their intervention efforts, typically at the mid-point and at the end of the intervention. Most of these interviews asked some close variation of the questions proposed in the overall design of the project and the responses provided evidence for mid-course refinements of district interventions, as well as evidence about outcomes. Most individual district reports include quite detailed responses to the interview questions and are a rich source of information about the experiences of parents, teachers and students as each set of interventions was being implemented.

Of greatest salience to the project as a whole is what the interview results suggest about outcomes of the interventions. First, much of this evidence indicates that, at the point of being officially completed, many participants believed that the value of the interventions was just beginning to be realized. This perception suggests that parent engagement strategies likely to be effective in nurturing student success at school need to engage parents and students deeply, either through their duration or intensity. A "light touch" does not seem likely to make much difference. More likely, these strategies should become a routine part of what schools do on a regular basis.

Second, those parents and teachers participating directly in the interventions often attributed greater value to the interventions than the more "objective" outcome data reported subsequently suggests. Furthermore, the significant weight most districts awarded these data in their individual reports exemplifies the well-documented claim that some types of evidence are just considered more salient than others as influences on decision making; qualitative data, for example, seem more meaningful to many than do quantitative data [34]. Knowing about this predictable bias in human decision making, future efforts to judge the value of parent engagement interventions should include multiple types of evidence.

\subsection{Student Perceptions of Changes in Family Educational Cultures}

Evidence from the student survey is the best indicator available of the impact of the project. The survey included multi-item scales measuring five variables. Two of these variables were dimensions of student engagement-behavioral engagement and psychological engagement or identification with school. The remaining variables measured by the survey were explicit goals to be achieved by the project including: increasing parental expectations for their children's success at school; the social and intellectual capital of parents and; communication between parents and students. These survey measures are aligned directly with project goals, provide evidence directly from students themselves, and are the only data common across all seven project districts.

Both treatment and control students in all schools responded to the survey near the beginning and at the end of their involvement in the project. Results of the survey are summarized in Table 3 (note that D2 had three sets of students included in its version of the project, hence three sets of data; the summary of results below refers to only the mean of the three scores for D2). All districts collected evidence about all five variables even though not all of these variables were explicitly included among the goals selected for their projects. 
Table 3. Cross-district Summary of Student Survey Results. Mean change scores of treatment $(\mathrm{T})$ and control $(\mathrm{C})$ groups (4 point rating scales).

\begin{tabular}{ccccccccccccc}
\hline Districts & \multicolumn{2}{c}{$\begin{array}{c}\text { Behav. } \\
\text { Engage't }\end{array}$} & \multicolumn{2}{c}{$\begin{array}{c}\text { Psych. } \\
\text { Engage't }\end{array}$} & \multicolumn{2}{c}{$\begin{array}{c}\text { High } \\
\text { Expect'n }\end{array}$} & \multicolumn{2}{c}{$\begin{array}{c}\text { Social/Intellectual } \\
\text { Capital }\end{array}$} & \multicolumn{2}{c}{$\begin{array}{c}\text { Parent/Child } \\
\text { Communication }\end{array}$} & $\begin{array}{c}\text { Mean } \\
\text { Change }\end{array}$ \\
\hline & $\mathrm{T}$ & $\mathrm{C}$ & $\mathrm{T}$ & $\mathrm{C}$ & $\mathrm{T}$ & $\mathrm{C}$ & $\mathrm{T}$ & $\mathrm{C}$ & $\mathrm{T}$ & $\mathrm{C}$ & T & $\mathbf{C}$ \\
\hline D1 & -0.01 & -0.14 & -0.25 & -0.08 & 0.00 & -0.09 & -0.07 & -0.02 & -0.02 & -0.11 & $-\mathbf{0 . 0 7}$ & $-\mathbf{0 . 0 8}$ \\
\hline D2* & & & & & & & & & & & & \\
A & 0.06 & -0.22 & 0.10 & -0.26 & -0.08 & -0.13 & 0.06 & -0.21 & 0.06 & -0.48 & $\mathbf{0 . 0 4}$ & $-\mathbf{0 . 2 6}$ \\
B & -0.17 & -0.12 & -0.16 & -0.18 & -0.24 & -0.11 & -0.13 & -0.04 & -0.27 & -0.12 & $-\mathbf{0 . 1 9}$ & $-\mathbf{0 . 1 6}$ \\
C & 0.09 & -0.15 & 0.04 & -0.17 & 0.10 & -0.15 & 0.18 & -0.05 & 0.21 & -0.17 & $\mathbf{0 . 1 2}$ & $-\mathbf{0 . 1 4}$ \\
Mean & -0.01 & -0.16 & -0.01 & -0.20 & 0.07 & -0.13 & 0.04 & -0.10 & 0.00 & -0.26 & $-\mathbf{0 . 0 1}$ & $-\mathbf{0 . 1 8}$ \\
\hline D3 & 0.20 & 0.00 & 0.08 & -0.07 & 0.02 & -0.01 & 0.43 & 0.05 & 0.29 & 0.49 & $\mathbf{0 . 2 1}$ & $\mathbf{0 . 0 9}$ \\
D4 & 0.26 & 0.39 & 0.11 & $\mathrm{NA}$ & 0.00 & 0.19 & 0.07 & 0.40 & 0.04 & 0.23 & $\mathbf{0 . 1 0}$ & $\mathbf{0 . 3 0}$ \\
D5 & 0.31 & -0.27 & 0.54 & -0.13 & 0.50 & -0.15 & 0.76 & -0.22 & 0.57 & -0.19 & $\mathbf{0 . 5 3}$ & $-\mathbf{0 . 3 0}$ \\
D6 & 0.27 & 0.06 & 0.05 & 0.07 & 0.03 & 0.06 & -0.02 & -0.23 & 0.12 & 0.05 & $\mathbf{0 . 0 9}$ & $-\mathbf{0 . 0 1}$ \\
D7 & 0.05 & -0.04 & 0.15 & 0.08 & 0.22 & -0.04 & 0.56 & 0.03 & 0.27 & 0.08 & $\mathbf{0 . 2 5}$ & $\mathbf{0 . 0 2}$ \\
\hline
\end{tabular}

* Group A = in-school plus summer school; Group B = in-school program only; Group C = summer learning program only.

Student behavioral engagement. Treatment groups in five of the seven districts made at least modest average gains in the behavioral dimension of student engagement as indicated in the first two columns of data in Table 3. In only one district did the results favor the control group students (D4). Of the three different intervention programs implemented by D2, the summer school only treatment group outperformed the other treatment and control groups with the in-school only alternative producing negative results. Because this is the pattern of results across all variables measured by the survey, the remaining report of the survey results takes into account only D2's average ratings, clearly ratings that mask the noteworthy differences in the impact of D2's three intervention programs.

Student psychological engagement. Treatment groups made at least modest average gains on the psychological dimension of student engagement in five of the seven districts. Negative "gains" by treatment groups were larger than control groups in one district (D1) and smaller in the other district (D2).

Parent expectations. Treatment groups in five districts made gains in parental expectations for student success at school while treatment groups in the two remaining districts made no change (D1 and D4). Treatment group changes also exceeded control group changes in five districts while D4 and D6 control group changes exceeded treatment group changes.

Parents' social and intellectual capital. Five of the seven treatment groups gained on this goal; only D1 and D6 treatment groups did not, although the D6 treatment group's losses were not nearly as large as the control group. Treatment group changes exceeded control groups changes in five districts.

Parent-child communications. Five of the seven treatment groups gained on this goal; only D1 and D2 treatment groups, on average, did not. Treatment group changes exceeded control group changes in five districts.

Across all districts, average results favored the treatment over the controls groups on $67 \%$ of the survey items with D2 results offering a more complex picture of the consequences of treatment variation. D2's summer school treatment resulted in substantially better student engagement results than results of the other D2 student groupings. 
This summary of student survey results supports the claim that, with one exception (D1), interventions by districts had, on average, positive effects; and in all but one district (D4), were modestly more successful in achieving the central goals of the project with treatment students as compared with control students.

In the case of D1, as the far right column of Table 3 indicates, both treatment and control group ratings declined from pre- to post-test and by almost identical amounts $(-0.07$ and -0.08$)$. This was the only district working with a secondary school population which may present both different and more significant challenges to the achievement of project goals than elementary school populations ${ }^{8}$. Another plausible explanation, however, one that would also apply to the weaker gains by D4's treatment as compared with control group results, is that the interventions implemented were largely "school driven", a category of interventions some previous evidence suggests has marginal effects on student outcomes [6]. However, student achievement evidence, described in the next section, provides some support for the strategies used by D4.

\subsection{Student Report Card Learning Skills}

Six learning skills are included on the provincial report cards used by all project schools. Table 4 compares average changes from pre- to post-test for all treatment and all control students in each of the four districts able to provide such evidence. The data from which these change scores are derived are based on numerical transformations of descriptive words or phrases used on report cards including Excellent $=4$, Good $=3$, Satisfactory $=2$ and Needs Improvement $=1$.

Table 4. Changes in Learning Skills Results by Treatment (T) and Control (C) Students.

\begin{tabular}{ccccccccc}
\hline \multirow{2}{*}{ Learning Skills } & \multicolumn{2}{c}{ D3 } & \multicolumn{2}{c}{ D4 } & \multicolumn{2}{c}{ D6 } & \multicolumn{2}{c}{ D7 } \\
\cline { 2 - 9 } & $\mathbf{T}$ & $\mathbf{C}$ & $\mathbf{T}$ & $\mathbf{C}$ & $\mathbf{T}$ & $\mathbf{C}$ & $\mathbf{T}$ & $\mathbf{C}$ \\
\hline Collaboration & 1.8 & 0.00 & 0.20 & 0.0 & 0.55 & -0.13 & -0.11 & 0.00 \\
Independent Work & 0.20 & 0.00 & 0.20 & 0.2 & 0.31 & -0.13 & 0.05 & -0.21 \\
Initiative & 0.05 & 0.20 & 0.00 & 0.0 & -0.08 & -0.19 & -0.23 & -0.06 \\
Organization & 0.10 & 0.16 & 0.20 & 0.2 & 0.27 & -0.11 & -0.18 & 0.00 \\
Responsibility & 0.01 & -0.15 & 0.00 & 0.0 & -0.13 & 0.03 & -0.23 & 0.10 \\
Self-Regulation & -0.03 & 0.00 & 0.10 & -0.2 & 0.25 & -0.27 & 0.12 & 0.21 \\
Mean & $\mathbf{0 . 3 5}$ & $\mathbf{0 . 0 4}$ & $\mathbf{0 . 1 2}$ & $\mathbf{0 . 0 3}$ & $-\mathbf{0 . 1 0}$ & $\mathbf{- 0 . 3 0}$ & $\mathbf{- 0 . 1 0}$ & $\mathbf{0 . 0 1}$ \\
\hline
\end{tabular}

Mean changes in ratings across all six learning skills in each of the four districts are found in the bottom row of Table 4. Data in this row indicate small improvements in learning skills ratings for both treatment and control students in two districts (D3 and D4), declines in such ratings for both groups in D6 (a larger decline for the control than the treatment students, however), and declines for the treatment group and a very slight increase for the control group in D7. Nonetheless, ratings of treatment students' learning skills exceed ratings of control students in three of the four districts. Treatment students made the greatest gains, as compared with control students, for the skills of Collaboration and Independent Work in all but D7.

8 For an outline of these differences and challenges, see Hill \& Tyson [35]. 
These results provide additional, albeit weak support for claims about the impact of three of the four districts' parent engagement interventions. Although the student engagement results for D4, described in the previous section, generally favored control over treatment students, the learning skills data included in Table 4 favor that district's treatment group.

\subsection{Student Report Card Subject Achievement}

Table 5 displays report card results in reading, writing (D6 reported a combined language score only), math and science (D7 and D6 only) before and after the districts' interventions for both treatment and control groups. These data, from four of the seven districts in the project, are based on the numerical transformations of letter grades typically used to report achievement on elementary school report cards. Grades ranged from $\mathrm{A}+$ to $\mathrm{D}^{-}$, a total of 12 possible grades. These letter grades were transformed to numbers by assigning $\mathrm{A}+=12, \mathrm{~A}=11, \mathrm{~A}^{-}=10$ and so on with $\mathrm{D}^{-}=1$. Results reported in Table 5 are average changes in these scores from pre- to post-test, usually a period of one term.

This is an admittedly truncated description of report card subject achievement data largely because subject classifications differed by district due, in part, to the reporting requirements at different grade levels. So only data about reading, writing and math are available across the four boards. Given these limitations, a very cautious interpretation of the data is warranted.

As the bottom row of Table 5 indicates, average changes in the subject achievement of treatment and control students was marginal in the four districts. However, these small changes favoured the treatment groups in three of the four districts. So these results provide at least weak support for claims about the impact of the parent engagement interventions on student achievement implemented in all but D3.

Table 5. Changes in Subject Achievement by Treatment (T) and Control (C) Students.

\begin{tabular}{ccccccccc}
\hline \multirow{2}{*}{ Subjects } & \multicolumn{2}{c}{ D3 } & \multicolumn{2}{c}{ D4 } & \multicolumn{2}{c}{ D6 } & \multicolumn{2}{c}{ D7 } \\
\cline { 2 - 9 } & T & C & T & C & T & C & T & C \\
\hline Reading & 1.0 & 1.0 & 1.2 & 0.6 & & & 0.12 & -0.1 \\
Writing & 1.0 & 0.0 & 0.3 & -1.4 & & & 0.18 & -0.21 \\
Language & & & & & -0.08 & 0.24 & & \\
Math & -2.0 & 2.0 & \multirow{2}{*}{$2.38^{* *}$} & -1.29 & -0.02 & -0.01 & $-0.53 * * *$ & -0.55 \\
Science & & & & & 0.11 & -0.49 & 0.12 & -0.61 \\
Mean & $\mathbf{0 . 0}$ & $\mathbf{1 . 0}$ & $\mathbf{0 . 9 6}$ & $\mathbf{0 . 7 0}$ & $\mathbf{0 . 0 3}$ & $-\mathbf{0 . 0 8}$ & $\mathbf{- 0 . 0 3}$ & $-\mathbf{0 . 3 7}$ \\
\hline
\end{tabular}

** The math change scores reported in this table for D4 are the average of separate scores reported for number sense, measurement, geometry, patterning, and data management; $* * *$ Number sense and numeration.

\section{Conclusions}

The three types of student outcome evidence summarized in the previous section (student engagement, learning skills and subject achievement) generally support a claim about the positive impact of the interventions implemented by project districts. Clearly, support for this claim is relatively weak and for two of the three types of evidence, does not include all seven districts. 
However, the more fulsome accounts of interviews with parents, students and teachers, found in the individual district reports, add some credence to this positive assessment of project effects.

Individual district reports included in the final project report [27] are a rich source of detailed information about how each district developed its interventions, the challenges experienced as those interventions were unfolding, as well as the consequences of such implementation. These reports also concluded with "lessons" for future work, typically fairly detailed lessons appropriate to their chosen interventions. However, these reports, as a whole, also suggest eight larger, overlapping lessons other districts might take heed of as they embark on their own parent engagement interventions ${ }^{9}$.

First, productively engaging parents as partners in the education of their children can be hard work. It is certainly quite different work for many school staffs. As Kruse and Louis [36] observe "deep-seated changes in the culture of schools are unlikely to occur without action to create more fundamental bonds with the community" (p. 7). Learning how to do this work well takes significant time and support. Schools and districts embarking on parent engagement efforts, targeted at improving student outcomes, should build in sufficient time and opportunity for staff learning and sometimes for staffs to undergo significant shifts in their attitudes toward the parents with whom they are likely to be working.

Second, efforts on the part of regular school staffs to build parents' social and intellectual capital related to schooling work best when a relatively generous amount of time during meetings, at the outset, is allowed for trust building among parents and between parents and the school staff.

Third, and overlapping the previous lesson, a handful of meetings with parents, no matter how well planned and executed, are unlikely to be sufficiently intensive, sensitive to parent perspectives or sustained to have much impact on student-related goals for parent engagement. Initiatives of this type, however, likely provide a good foundation for follow-up initiatives aimed directly, for example, at building parents' social capital, fostering higher expectations for their children's success at school, and nurturing productive communication between parents and children in the home. Such truncated initiatives provide the opportunities for learning, attitude change and the starting points for trust building needed to subsequently make a difference for students in partnership with parents. But they are of little value by themselves.

Fourth, the duration of efforts to engage parents productively in the education of their children may be less important than the intensity and focus of those efforts. Intense efforts within a relatively short period can pay off when they occur either inside or outside the home, as long as they provide direct, practical help to parents in supporting their child's work at school. This lesson is most suitable for efforts that do not depend exclusively for their implementation on regular school staffs. The importance of a sharp focus on how to be successful at school is mirrored in a significant amount of previous research. For example, Hill and Tyson's [35] meta-analysis found stronger effects on student achievement of "academic socialization" approaches to parent engagement than a wide range of other approaches included in their analysis.

Fifth, within any of the broad approaches to parent engagement that might be chosen, effective implementation strategies are likely to be dynamic. To build productive partnerships with parents, a

9 These lessons should be considered provisional, of course, because of the small size of the sample from on which they are based. 
concept discussed by Ferlazzo [20], schools need to carefully plan their initial contacts but assume that those plans are likely to need changing as their knowledge about parent and student needs grows. Flexibility is a critical quality for schools to bring to their parent engagement efforts.

Sixth, engaging parents of secondary students and developing partnerships with them in the interests of their children's success at school is typically more complicated —or at the very least, different - than it is with parents of elementary school children. But secondary teachers who are pessimistic initially about the feasibility of developing such partnerships may become strong advocates for the effort with a willingness to persist long enough to make significant progress. This lesson is also reflected in a significant amount of previous research on parent engagement which takes account of differences in students' stage of development (see for example [35]).

Seventh, while many First Nations parents and children face huge challenges related to poverty and sometimes to location, many such parents are highly motivated to increase their social and intellectual capital related to the schooling of their children and readily build on opportunities to improve those conditions in the home which foster their children's success at school. In their comprehensive report of approaches to the improvement of education for indigenous peoples in Alberta, Gunn et al. [37] discuss specific and effective strategies: making communication with Aboriginal parents a priority, and substantial attention to creating a sense of belonging and enhancing cultural awareness. Understanding Aboriginal people and the traditional ways of life and culture help to create effective communications between the staff and Aboriginal parents [38].

Finally, communications between parents and schools are central to productive parent-school partnerships but there is no one form or even several forms that work well in all circumstances and with all parents. Schools should ask their parents what forms of communication work best for them and stay tuned for changes in the answers. As Ferlazzo, [20] notes "A school striving for parent engagement...tends to lead with its ears-listening to what parents think, dream, and worry about. The goal of family engagement is not to serve clients but to gain partners" (p. 10).

The eight lessons described here are the most obvious insights to be gleaned from the work of the project districts.

\section{Acknowledgements}

This project was funded by the Ontario Ministry of Education. None of the funds received were to cover the cost to publish the paper in an open access journal. Each of the seven participating districts conducted an ethical review of the research proposal using procedures established in each district.

\section{Author Contributions}

This paper is based on a study conducted in seven Ontario school districts led by Kenneth Leithwood. Both authors have read and approved the final manuscript and have contributed equally to this work.

\section{Conflicts of Interest}

The authors declare no conflict of interest. 


\section{Appendix A}

\begin{tabular}{|c|c|}
\hline \multicolumn{2}{|c|}{$\begin{array}{rr} & \text { Student Survey } \\
\end{array}$} \\
\hline \multicolumn{2}{|c|}{ Behavioral Engagement } \\
\hline \multicolumn{2}{|c|}{ Respond to Requirements } \\
\hline 1 & I rarely daydream in my classes. \\
\hline 2 & I rarely am late for school. \\
\hline 3 & I always finish my school work on time. \\
\hline 4 & I do all the homework that I am supposed to do. \\
\hline 5 & I respond whenever I am asked questions during class. \\
\hline 6 & I rarely am absent for a whole day. \\
\hline 7 & I rarely am sent to the office because of misbehaviour. \\
\hline 8 & I rarely skip a class (without permission). \\
\hline 9 & I rarely receive a detention. \\
\hline 10 & I rarely stay home unless I am sick. \\
\hline \multicolumn{2}{|c|}{ Class-related Initiative } \\
\hline 11 & I put a lot of energy into my schoolwork. \\
\hline 12 & I enjoy giving my opinion during class discussions. \\
\hline 13 & I frequently ask questions during class. \\
\hline 14 & I frequently have discussions with my teacher about things I find interesting. \\
\hline 15 & I frequently do extra schoolwork to find out more about something that interests me. \\
\hline 16 & I do a lot of extra reading for my own benefit. \\
\hline \multicolumn{2}{|c|}{ Psychological Engagement } \\
\hline \multicolumn{2}{|c|}{ Sense of Belonging } \\
\hline 17 & I feel that I "belong" at this school. \\
\hline 18 & Most of my teachers are interested in me as a person. \\
\hline 19 & I have made many friends in my school. \\
\hline 20 & Most of my teachers treat me the same as other students. \\
\hline 21 & Most of my teachers make me feel comfortable in class. \\
\hline 22 & I have gotten to know other students in our school really well. \\
\hline 23 & I get along with most other students I have met at school. \\
\hline 24 & My teachers spend time just talking with me. \\
\hline 25 & Most of my teachers seem to understand me. \\
\hline 26 & I get along with most of my teachers. \\
\hline \multicolumn{2}{|r|}{ Student Survey } \\
\hline \multicolumn{2}{|r|}{ Valuing School } \\
\hline 27 & The most important things that happen to me usually happen at school. \\
\hline 28 & I think schoolwork is really important. \\
\hline 29 & It is really important to me that I gain knowledge and develop skills. \\
\hline 30 & I am proud of my school. \\
\hline 31 & I really enjoy school most of the time. \\
\hline 32 & All people should get as much education as they can. \\
\hline 33 & School spirit is very high in my school. \\
\hline \multicolumn{2}{|c|}{ High Expectations } \\
\hline 34 & My parents/guardians make sure I do my homework before having free time. \\
\hline 35 & My parents/guardians always know whether or not I am at school. \\
\hline
\end{tabular}




\begin{tabular}{|l|l|}
\hline \multicolumn{2}{|c|}{ Student Survey } \\
\hline 36 & My parents/guardians make sure that I get to school on time. \\
\hline 37 & My parents/guardians make sure that I attend school unless I am sick. \\
\hline 38 & $\begin{array}{l}\text { My parents/guardians contact my school when I am having difficulty or when they are not } \\
\text { sure of how they can help me. }\end{array}$ \\
\hline 39 & My parents/guardians encourage me to participate in extracurricular activities. \\
\hline 40 & Study aids that I have at home help me do better schoolwork. \\
\hline 41 & I have my own work space at home that is fairly quiet for doing school work. \\
\hline Social/Intellectual Capital \\
\hline 42 & My parents/guardians usually go to parents' nights and special school events. \\
\hline 43 & I often discuss my schoolwork with my parents/guardians. \\
\hline 44 & My parents/guardians ensure that I have a healthy diet and enough sleep. \\
\hline 45 & My parents/guardians often talk with other parents about what is happening at school. \\
\hline 46 & My parents/guardians often discuss my work at school with my teacher. \\
\hline & Communication \\
\hline 47 & My parents/guardians always are willing to help me with my schoolwork. \\
\hline 48 & I talk with my parents/guardians about what I am doing at school almost every day. \\
\hline 49 & $\begin{array}{l}\text { I have conversations about what is happening in my community and the wider world with } \\
\text { my parents/guardians. }\end{array}$ \\
\hline 50 & My parents/guardians listen to my ideas. \\
\hline 51 & My parents/guardians encourage me to take responsibility for my own learning at school. \\
\hline 52 & My parents/guardians encourage me not to give up when I am having difficulty at school. \\
\hline
\end{tabular}

\section{References and Notes}

1. Coleman, J.; Campbell, E.; Hobson, C.; McPartland, J.; Mood, A.; Weinfeld, F.; York, R. Equality of Educational Opportunity; U.S. Government Printing Office: Washington, DC, USA, 1966.

2. Leithwood, K.; Jantzi, D. The relative effects of principal and teacher sources of leadership on student engagement with school. Educ. Adm. Q. 1999, 35, 679-706.

3. Hattie, J. Visible Learning: A Synthesis of over 800 Meta-Analyses Relating to Achievement; Routledge: London, UK, 2009.

4. Epstein, J.; Sanders, M.; Simon, B.; Salinas, K.; Jansorn, N.; Van Voorhis, F. School, Community, and Community Partnerships: Your Handbook for Action, 2nd ed.; Corwin: Thousand Oaks, CA, USA, 2002.

5. Henderson, A.; Mapp, K.L. A New Wave of Evidence: The Impact of School, Family, and community Connections on Student Achievement (Annual Synthesis); National Center for Family \& Community Connections with Schools: Austin, TX, USA, 2002.

6. Ma, X.; Shen, J.; Krenn, H. The relationships between parental involvement and adequate yearly progress among urban, suburban and rural schools. School Eff. School Improv. 2013, 25, 629-650.

7. Bolivar, J.; Chrispeels, J. Enhancing parent leadership through building social and intellectual capital. Am. Educ. Res. J. 2011, 48, 4-38.

8. Fan, X.; Chen, M. Parent involvement and students' academic achievement: A meta-analysis. Educ. Psychol. Rev. 2001, 13, 1-22. 
9. Harris, A.; Andrew-Power, K.; Goodall, J. Do Parents Know They Matter? Raising Achievement through Parental Engagement; Continuum International Publishing Group: London, UK, 2009.

10. Hoover-Dempsey, K.V.; Walker, J.M.T.; Sandier, H.M.; Whetsel, D.; Green, C.L.; Wilkins, A.S.; Closson, K. Why Do Parents Become Involved? Research Findings and Implications. Elementary School J. 2009, 106, 105-130.

11. Mapp, K.L. Having Their Say: Parents Describe How and Why They Are Involved in Their Children's Education. Presented at the Annual Meeting of the American Educational Research Association, New Orleans, LA, USA, 1-5 April 2002.

12. Epstein, J.; Dauber, S. School Programs and Teacher Practices of Parent Involvement. Elementary School J. 1991, 91, 289-305.

13. Jeynes, W. A meta-analysis of the relation of parent involvement to urban elementary school student academic achievement. Urban Educ. 2005, 40, 237-269.

14. Freeman-Loftis, B. How to really listen to parents. ASCD J. 2011, 8. Available online: http://www.ascd.org/publications/educational-leadership/may11/vol68/num08/How-to-(Really)Listen-to-Parents.aspx (accessed on 30 June 2015).

15. Cooper, C.W.; Riehl, C.J.; Hasan, A.L. Leading and learning with diverse families in schools: Critical epistemology amid communities of practice. J. School Leadersh. 2010, 20, 758-788.

16. Bandura, A. Social Foundations of Thought and Action; Prentice Hall: Englewood Cliffs, NJ, USA, 1986.

17. Hornby, G.; Lafaele, R. Barriers to parental involvement in education: An explanatory model. Educ. Rev. 2011, 63, 37-52.

18. Lee, J.; Bowen, N. Parent involvement, cultural capital and the achievement gap among elementary school children. Am. Educ. Res. J. 2006, 43, 193-218.

19. Coleman, J. Social capital in the creation of human capital. Am. J. Sociol. 1988, 94, S95-S120.

20. Ferlazzo, L. Involvement or Engagement? ASCD J. 2011, 68, 10-14.

21. Hoover-Dempsey, K.V.; Sandler, H.M. Why do parents become involved in their children's education? Rev. Educ. Res. 1997, 67, 3-12.

22. Johnson, S. Future Perfect: The Case for Progress in Networked Age; Riverhead Books: New York, NY, USA, 2012.

23. Lawson, M.A.; Alameda-Lawson, T.A. Case Study of School-Linked, Collective Parent Engagement. Am. Educ. Res. J. 2012, 49, 651-684.

24. Bronfenbrenner, U. Ecological models of human development. In International Encyclopedia of Education, 2nd ed.; Elsevier: Oxford, UK, 2005; Volume 3, pp. 1643-1647.

25. Niehaus, K.; Adelson, J. School support, parent involvement and academic and social-emotional outcomes for English language learners. Am. J. Educ. Res. 2014, 51, 810-844.

26. Dunleavy, J; Willms, J.D.; Milton, P; Friesen, S. What Did You Do In School Today? Research reports leveraged by the Canadian Education Association. Available online: http://www.ceaace.ca/programs-initiatives/wdydist (accessed on 3 September 2015).

27. Leithwood, K. Ontario Parent Engagement Project, Final Report of Research for the Ontario Ministry of Education; Ontario Ministry of Education: Toronto, ON, Canada, 2014.

28. Jeynes, W. Parental Involvement and Academic Success; Routledge: New York, NY, USA, 2011

29. Finn, J. Withdrawing from School. Rev. Educ. Res. 1989, 59, 117-143. 
30. Leithwood, K.; Jantzi, D. The effects of transformation leadership on student engagement with school. J. Educ. Adm. 2000, 38, 112-129.

31. Turner, J.; Christensen, A.; Kackar-Cam, H.; Turcano, M.; Fulmer, S. Enhancing students' engagement: Report of a 3-year intervention with middle school teachers. Am. Educ. Res. J. 2014, 51, 1195-1226.

32. Willms, J.D. Student Engagement at School: A Sense of Belonging and Participation; Organization for Economic Co-operation and Development: Paris, France, 2003.

33. Leithwood, K.; Jantzi, D. A Critical Review of the Parent Engagement Literature, Final Report of Research for the Ontario Ministry of Education; Ontario Ministry of Education: Toronto, ON, Canada, 2006.

34. Kahneman, D. Thinking Fast and Slow; Farrar, Straus and Giroux: New York, NY, USA, 2011.

35. Hill, N.; Tyson, D. Parental involvement in middle school: A meta-analytic assessment of the strategies that promise achievement. Dev. Psychol. 2009, 45, 740-763.

36. Kruse, S.D.; Louis, S.K. Building Strong School Cultures: A Guide to Leading Change; SAGE: Thousand Oaks, CA, USA, 2006.

37. Gunn, T.M.; Pomahac, G.; Striker, E.G.; Tailfeathers, J. First Nations, Metis, and Inuit education: The Alberta initiative for school improvement approach to improve Indigenous education in Alberta. J. Educ. Chang. 2011, 12, 323-345.

38. Agbo, S.A. Addressing school-community relations in a cross-cultural context: A collaborative action to bridge the gap between First Nations and the school. J. Res. Rural Educ. 2007, 22, 1-14.

(C) 2015 by the authors; licensee MDPI, Basel, Switzerland. This article is an open access article distributed under the terms and conditions of the Creative Commons Attribution license (http://creativecommons.org/licenses/by/4.0/). 